\title{
Kinerja Sanitarian Puskesmas
}

\author{
Ardinal*
}

\begin{abstract}
Abstrak
Program penyehatan air bersih dilaksanakan untuk pemenuhan akses masyarakat terhadap air bersih yang mencakup aspek jumlah dan kualitas. Untuk itu, perlu kerja keras pemegang program penyehatan air, khususnya sanitarian puskesmas yang merupakan ujung tombak pelaksanaan program di puskesmas. Tujuan penelitian ini mendapatkan gambaran kinerja petugas sanitasi Puskesmas dan faktor-faktor yang berperan di Kabupaten Solok Tahun 2007. Penelitian ini menggunakan pendekatan kualitatif melalui wawancara mendalam, Diskusi Kelompok Terarah dan observasi, dengan informan sanitarian puskesmas dilanjutkan triangulasi sumber dengan Kepala Puskesmas dan Kepala Bidang PL \& PKM Dinas Kesehatan Kabupaten Solok. Kinerja sanitarian puskesmas dalam pelaksanaan program penyehatan air bersih yang rendah terlihat pada cakupan rendah, penyuluhan kurang, pembinaan pokmair kurang, pengawasan air kurang, sistem informasi program tidak jalan. Faktor yang berperan dalam kinerja sanitarian meliputi; kemampuan dan keterampilan kurang, supervisi dari Kabupaten dan Puskesmas kurang; pelatihan sanitarian yg kurang dan tidak sesuai kebutuhan, motivasi sanitarian rendah, imbalan dan dana operasional kurang, beban kerja tambahan, sarana dan prasarana tidak memadai, prioritas program kurang, akses wilayah kecamatan terisolir tidak lancar, serta program air bersih yang belum prioritas.
\end{abstract}

Kata kunci : Program penyehatan air bersih, petugas sanitasi, air bersih

\begin{abstract}
Healthy and hygienic water program is implemented to fulfill public access to hygienic water, not only in quantity but also the quality of hygienic water consumed by public. This study aim is to describe performance of sanitation officer in community health center and factors related in Solok District in 2007. This study used qualitative method by in-depth interview, focus group discussion and observation; informant is sanitation officer in community health center, which was source-triangulated with the head of community health center and head of PL and PKM of District Health Office. Low performance of sanitation officer was reflected in low coverage, low frequency of counseling, low frequency of community training, low frequency of water monitoring, information system program was not functioned well. Factors which are important on sanitation officer performance include: less ability and skill of sanitation officer, less supervision of district and community health center head, less training frequency of sanitation officer and the need is not matched, low motivation of sanitation officer, less reward and operational fund, many extra jobs, facility and basic facility are not adequate, less program priority by head of community health center, access to several working areas is not good especially in the isolated sub-district, and budget policy of District Health Office which is not prioritizing sufficient budget for health and hygienic water program.
\end{abstract}

Key words : Healthy and hygienic water program, sanitation officer, hygienic water

*Seksi Pengendalian Penyakit Dinas Kesehatan Kabupaten Solok Sumatera Barat, Jl. Komplek Perkantoran Pemda Kabupaten Solok Arusuka (e-mail: stbgd@yahoo.co.id) 
Pada era desentralisasi, kewenangan upaya kesehatan lingkungan telah diserahkan kepada pemerintah daerah. Hal tersebut memerlukan peran besar pemerintah daerah kabupaten/kota dengan segenap jajarannya yang mencakup dinas kesehatan sampai dengan tingkat puskesmas. Peraturan Presiden Nomor 7 Tahun 2005 tentang Rencana Pembangunan Jangka Menengah Nasional (RPJMN) tahun 2004-2009 memuat 10 program yang diamanatkan kepada Departemen Kesehatan. Salah satu program tersebut adalah program lingkungan sehat yang tertuang dalam Rencana Strategis Departemen Kesehatan tahun 2005-2009. ${ }^{1}$ Salah satu kegiatan program lingkungan sehat tersebut adalah penyediaan sarana air bersih dan sanitasi dasar. Upaya tersebut perlu mendapat perhatian besar, mengingat permasalahan pembangunan air bersih yang semakin kompleks.

Saat ini, upaya penyehatan air yang diberikan pada masyarakat pelanggan eksternal mutlak diperlukan. Atribut yang harus diperhatikan dalam perbaikan kualitas jasa antara lain meliputi ketepatan waktu, akurasi, kesopanan dan keramahan, tanggung jawab, kelengkapan, kemudahan, variasi pelayanan dan kenyamanan layanan. ${ }^{2}$ Kinerja sanitarian puskesmas berpengaruh sangat besar dalam peningkatan pencapaian program penyehatan air bersih di wilayah kerja puskesmas. Untuk mendapatkan hasil yang optimal, kinerja sanitarian sebagai perencanaan program penyehatan air bersih tingkat kabupaten harus ditingkatkan dengan melihat cakupan hasil kerja sanitarian di puskesmas.

Peningkatan kinerja dipengaruhi oleh beberapa faktor antara lain meliputi karakteristik individu, motivasi, gaji, keluarga, organisasi dan pengembangan karier. ${ }^{3}$ Beberapa faktor yang mempengaruhi kinerja meliputi faktor individu, psikologis, dan organisasi. Faktor - faktor individu meliputi kemampuan dan keterampilan, latar belakang keluarga, tingkat sosial, pengalaman dan karakteristik demografi (umur, etnis, jenis kelamin). Faktor psikologis antara lain persepsi, sikap, kepribadian dan motivasi. Faktor organisasi meliputi sumber daya, kepemimpinan, imbalan, struktur dan desain pekerjaan. ${ }^{4}$

Indikator kinerja dinas kesehatan di kabupaten/kota secara umum mengacu pada Keputusan Menteri Kesehatan RI Nomor 1457/2003 tentang kewenangan wajib dan Standar Pelayanan Minimal (SPM). Target pelayanan kesehatan lingkungan yang harus dicapai sampai tahun 2010 adalah $70 \%$ dari institusi yang dibina. Pencapaian target tersebut dilaksanakan melalui kegiatan penyuluhan, inspeksi sanitasi, pengambilan sampel air, tindak lanjut serta monitoring dan evaluasi. Kegiatan tersebut dilakukan oleh tenaga sanitasi puskesmas melalui kegiatan pelayanan dalam gedung dan luar gedung. ${ }^{5}$ Cakupan program penyehatan air bersih
Kabupaten Solok Tahun 2006 adalah 52,37\% atau 40.109 Kepala Keluarga (KK). Jumlah Kepala Keluarga dengan SAB yang diinspeksi sanitasi adalah $16.808 \mathrm{KK}$ $(41,91 \%){ }^{6}$

Kinerja tenaga pengelola program penyehatan air di Kabupaten Solok, khususnya tenaga sanitarian puskesmas yang masih rendah perlu dilakukan analisis melalui suatu penelitian yang sampai kini belum pernah dilaksanakan di Kabupaten Solok.

\section{Metode}

Penelitian ini menggunakan pendekatan kualitatif dengan sumber data primer dan sekunder. Data primer dikumpulkan dengan wawancara mendalam, Diskusi Kelompok Terarah (DKT) dan observasi. Data sekunder didapat dengan telaah yang dilakukan terhadap delapan belas unit puskesmas di wilayah kerja Dinas Kesehatan Kabupaten Solok. Informan yang disertakan adalah sanitarian terampil di puskesmas. Diskusi Kelompok Terarah dan observasi menggunakan daftar tilik (check list). Instrumen utamanya adalah penulis. ${ }^{7}$ Uji validitas/triangulasi dilakukan dengan triangulasi metode dan triangulasi sumber.

Pengumpulan data primer dilakukan dengan metoda wawancara mendalam berdasarkan kecukupan informasi pada sanitarian terampil puskesmas dan Diskusi Kelompok Terarah (DKT). Untuk mengkonfirmasi informasi dari sanitarian dilakukan wawancara mendalam pada Kepala Puskesmas dan Kepala Bidang Penyuluhan Kesehatan Masyarakat dan Penyehatan Lingkungan (PKM \& PL) Dinas Kesehatan Kabupaten Solok. Observasi dilakukan terhadap upaya penyehatan air yang meliputi inspeksi sanitasi, pengambilan, pengiriman, pemeriksaan sampel air, penyuluhan, pembinaan kelompok pemakai air yang dilakukan oleh sanitarian di luar gedung maupun di dalam gedung. Pertanyaan wawancara mendalam dan Diskusi Kelompok Terarah (DKT) mengacu pada pertanyaan yang disusun berdasarkan kerangka konsep. Untuk menghindari bias pelaksanaan wawancara mendalam dan Diskusi Kelompok Terarah (DKT) peneliti dibantu oleh tiga orang pembantu pencatatan yang telah dilatih. Data wawancara mendalam dan Diskusi Kelompok Terarah (DKT) dibandingkan dengan hasil kegiatan bulanan pengawasan kualitas air, perbaikan kualitas air dan pembinaan pemakai air pada tahun 2006.

Langkah analisa data kualitatif yang dilakukan meliputi pembuatan transkrip hasil wawancara mendalam, menandai dan mengelompokan data yang mempunyai pola yang sama. Menyajikan ringkasan data dalam bentuk matrik/tabel dan dapat diuraikan kembali dalam bentuk narasi atau katagorisasi. Mengidentifikasikan persamaan, perbedaan dan kecendrungan antar variabel dengan melaksanakan interprestasi data. 


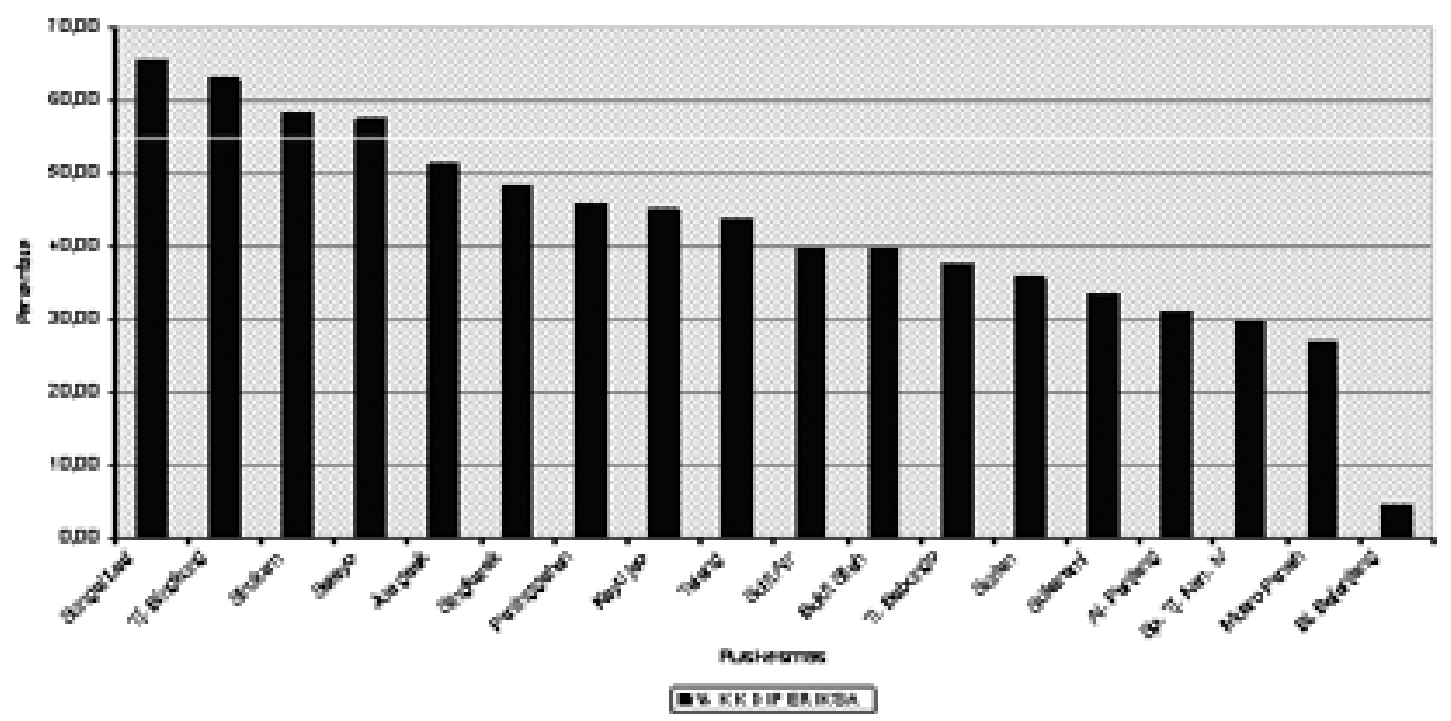

Gambar 1. Cakupan Inspeksi Sanitasi per Puskesmas di Kabupaten Solok Tahun 2006

\section{Hasil}

Letak Geografis dan Kependudukan

Kabupaten Solok merupakan salah satu kabupaten di Provinsi Sumatera Barat, membentang dari arah Barat Daya ke Tenggara, tepatnya berada pada $01^{\circ} 20^{\prime \prime} 27$ " $01^{\circ} 21^{\prime}$ 39” LS dan $100^{\circ} 33^{\prime} 43^{\prime}$ " BT. Ketinggian 329 1.458 meter di atas permukaan laut. Curah hujan 565 $2.735 \mathrm{~mm} /$ tahun. Dengan luas wilayah $3.738 \mathrm{~km}^{2}$ yang terbagi dalam 14 kecamatan 74 nagari dan 407 jorong. Sejumlah nagari tersebut, 17 nagari diantaranya $(22,7 \%)$ masih merupakan nagari tertinggal. Wilayah Kabupaten Solok berbatasan di sebelah utara dengan Kabupaten Tanah Datar, sebelah selatan dengan Kabupaten Solok Selatan, sebelah barat dengan Kota Padang dan Pesisir Selatan, dan sebelah timur dengan Kabupaten Sawah Lunto Sijunjung \& Kota Sawahlunto. Hasil Sensus Penduduk tahun 2000 dan SUPAS tahun 2005 oleh Badan Pusat Statistik Kabupaten Solok, penduduk Kabupaten Solok pada tahun 2006 sebesar 342.940 jiwa dengan laju pertumbuhan penduduk $1,3 \%$ per tahun. ${ }^{8}$ Pada tahun 2006, penyebaran penduduk tertinggi $(2,44 \% ; 8.354$ jiwa). Kepadatan penduduk tertinggi di Kecamatan Lembang Jaya $\left(320,10\right.$ orang $\left./ \mathrm{km}^{2}\right)$ dan terendah di Kecamatan X Koto (114,46 orang $/ \mathrm{km}^{2}$ ).

Tahun 2004 terjadi Kejadian Luar Biasa (KLB) diare dengan penderita yang dirawat 263 kasus dan meninggal dunia 4 orang, ${ }^{1}$ sedangkan kasus diare untuk tahun 2005 adalah 9.916 kasus serta tahun 2006 sebanyak 7.843 kasus. Diare menempati urutan ketiga penyakit terbanyak di Kabupaten Solok Tahun 2006 yaitu $10,24 \%$ atau 7.843 kasus. Cakupan air bersih di
Kabupaten Solok tahun 2006 sebesar 52,37\% mengakses $40.109 \mathrm{KK}$ dengan cakupan tertinggi di wilayah kerja Puskesmas Jua Gaek 85,54\% dan terendah di Puskesmas Talang Babungo yaitu 16,69\%. Perbandingan kinerja sanitarian pelaksanaan program upaya penyehatan air dalam 3 tahun terakhir (20042006) tidak dapat dilakukan karena ketiadaan data. Cakupan Inspeksi Sanitasi (IS) di Kabupaten Solok tahun 2006 tertinggi di wilayah kerja Puskesmas Sungai Lasi $(65,62 \%)$ dan terendah di wilayah kerja Puskesmas Batu Bajanjang Kecamatan Tigo Lurah jauh di bawah angka rata-rata cakupan inspeksi sanitasi Kabupaten Solok $(55 \%)$ (Lihat Gambar1).

Kegiatan pemeriksaan sampel air pada tahun 2006 relatif sangat sedikit daripada hasil tingkat risiko pencemaran rendah dan sedang inspeksi sanitasi. Pada tahun 2006, dilakukan pemeriksaan 76 sampel air, 49 sampel kimia dan 27 sampel bakteriologis. Berdasarkan jenis sarana, pemeriksaan kualitas air bersih tertinggi di Kabupaten Solok adalah sampel air dari sarana Sumur Gali (SGL) $(0,26 \%)$ dan yang terendah adalah sampel air PDAM $(0,09 \%)$. Tidak dilakukan pengambilan dan pemeriksaan sampel air sarana SPT, PMA, PAH, air kemasan dan air isi ulang. Jumlah pemeriksaan sampel air bakteriologis pada tahun 2004, 2005 dan 2006 masingmasing adalah 210, 230 dan 76 sampel air dan yang memenuhi syarat adalah $63,81 \% ; 70,87 \%$ serta $56,58 \%$. Apabila dibandingkan dengan kondisi pada tiga tahun terakhir persentase pengambilan sampel air terlihat semakin menurun. Persentase kualitas bakteriologis sampel air per jenis sarana yang memenuhi syarat di Kabupaten 
Solok tahun 2006 tertinggi adalah sarana perpipaan non PDAM dan SG masing-masing 50\% dan yang terendah adalah sarana perpipaan PDAM (20\%).

Persentase risiko pencemaran sarana non perpipaan di Kabupaten Solok tahun 2006 yang tertinggi terdapat di wilayah kerja Puskesmas Surian Kecamatan Pantai Cermin $(74,31 \%)$ dan yang terendah di Puskesmas Tanjung Bingkung Kecamatan Kubung. Kelompok Pemakai Air (Pokmair) yang ada di Kabupaten Solok (247 kelompok; 38,2\%) dan Pokmair yang aktif (46,2\% atau 114 kelompok). Kelompok pemakai air yang aktif di Kabupaten Solok tahun 2006 tertinggi di wilayah kerja Puskesmas Selayo Kecamatan Kubung $(62,5 \%)$ dan yang terendah di wilayah kerja Puskesmas Talang Babungo $(0,0 \%)$.

\section{Faktor Individu, Organisasi dan Psikologis}

Kinerja sanitarian puskesmas melaksanakan program penyehatan air bersih dapat dilihat dari cakupan IS rendah, penyuluhan kurang, pembinaan Pokmair kurang, pengawasan air kurang, sistem informasi program tidak jalan. Faktor yang berperan pada kinerja tersebut meliputi: (1) Kemampuan dan keterampilan yang kurang terasah akibat supervisi dari kabupaten dan kepala puskesmas yang kurang; frekuensi pelatihan sanitarian yang kurang dan tidak sesuai dengan kebutuhan di lapangan. (2) Motivasi kerja sanitarian yang rendah terjadi akibat imbalan dana operasional yang kurang; sarana dan prasarana tidak memadai; supervisi dinas kesehatan dan kepala puskesmas yang kurang serta prioritas program di puskesmas yang rendah. (3) Akses sebagian wilayah kerja kecamatan terisolir tidak lancar karena sarana dan prasarana transportasi yang kurang. (4) Kebijakan anggaran dinas kesehatan belum memprioritaskan anggaran program kesehatan lingkungan atau program air bersih. Hal tersebut mengakibatkan kuantitas sarana dan prasarana pendukung yang kurang, pelaksanaan supervisi oleh dinas kabupaten terhambat, dana operasional puskesmas yang terbatas, pelaksanaan program pelatihan yang kurang. (5) Sikap sanitarian terlihat positif, tapi pelaksanaan program masih kurang sebagai akibat pengawasan kepala puskesmas yang kurang dan rasa tanggung jawab sanitarian terhadap program yang kurang.

\section{Pembahasan}

Observasi kegiatan sanitarian di lapangan seperti inspeksi sanitasi dan penyuluhan, peneliti harus menunggu jadwal sanitarian ke lapangan. Observasi kegiatan pengambilan, pengiriman dan pemeriksaan sampel air di lapangan tidak dapat dilakukan pada semua sanitarian karena tidak dilaksanakan oleh semua puskesmas yang diamati. Jawaban informan ada yang tidak konsisten, sehingga menyulitkan pengambilan kesim- pulan topik yang dibahas. Daerah dengan cakupan air bersih yang rendah seperti wilayah kerja Puskesmas Talang Babungo dan puskesmas lain, hendaknya menjadi perhatian pemerintah Kabupaten Solok dengan menjadikannya lokasi program penyediaan air bersih yang saat ini sedang dilaksanakan di Kabupaten Solok, (Proyek PPK, WSLIC2) serta proyek yang didanai oleh APBD.

Salah satu pemecahan masalah peningkatan cakupan inspeksi sanitasi adalah melengkapi sanitarian dengan sarana transportasi ke lapangan serta biaya operasional dari APBD kabupaten dan PKPS BBM puskesmas. Di samping itu, peran supervisi kepala puskesmas dan dinas kesehatan perlu dilakukan secara kontinyu dan dapat memberikan motivasi dalam bekerja. Sebagai penentu kebijakan, Dinas Kesehatan Kabupaten Solok hendaknya dapat mengalokasikan dana pemeriksaan sampel yang berasal dari hasil inspeksi sanitasi rendah dan sedang, agar target pemeriksaan sampel kabupaten minimal $(30 \%)$ dari hasil IS rendah dan sedang dapat tercapai.

Untuk meningkatkan kualitas bakteriologis air bersih perlu dilakukan program desinfektan air bersih dengan pembubuhan kaporit oleh dinas kesehatan kabupaten dan masyarakat dengan bimbingan sanitarian puskesmas. Program pembinaan dan penyuluhan pada masyarakat juga dapat dilakukan guna meningkatkan kualitas sarana air bersih yang digunakan. Penyuluhan dapat dilakukan pada saat kunjungan IS, di Klinik Sanitasi, PKK, pengajian dan di posyandu. Hal tersebut perlu didukung oleh sarana penyuluhan yang memadai baik cetak maupun elektronik. Upaya menggerakan Pokmair masyarakat difasilitasi oleh sanitarian puskesmas dan kelompok dasa wisma adalah mengadakan pendekatan kepada tokoh masyarakat yang meliputi tokoh pemuda, alim ulama, ninik mamak dan bundo kandung sebagai tokoh yang berperan di tengah masyarakat.

Kegiatan pendukung program pengembangan lingkungan sehat adalah dengan kegiatan sosialisasi dan pelaksanaan lingkungan sehat yang dimulai dari kecamatan sehat sampai Nagari Sehat, yang sangat ditentukan oleh keberhasilan program penyehatan air kecamatan atau nagari. Indikator penyediaan air bersih individu dan umum kabupaten sehat yang harus dicapai adalah: peningkatan cakupan air bersih; peningkatan cakupan kualitas air minum yang memenuhi syarat kesehatan; peningkatan proporsi masyarakat yang memeriksakan air ke laboratorium; dan penurunan kasus diare. $^{9}$

Upaya pemantapan dan pengembangan sistem informasi kesehatan diarahkan untuk berhasil guna, akurat, tepat waktu dan dalam bentuk yang sesuai kebutuhan pengambilan keputusan di seluruh tingkat administrasi untuk perencanaan, penggerakan, pelaksanaan, penga- 
wasan, pengendalian dan penilaian; mengatasi masalah kesehatan melalui isyarat dini dan upaya penanggulangan. Pelaksanaan sistem informasi kesehatan di kabupaten perlu dilaksanakan dengan mengaktifkan kembali bidang perencanaan pada dinas kesehatan kabupaten, untuk mengelola dan menyajikan informasi kesehatan yang berasal dari data kegiatan/program yang pelaksanaannya mengacu pada Kewenangan Wajib Standar Pelayanan Minimal (KWSPM) sebagai indikator kinerja organisasi kesehatan, sehingga informasi kesehatan dapat dengan mudah diakses bagi siapa saja yang membutuhkan.

\section{Faktor Individu}

Kemampuan dan keterampilan sanitarian puskesmas di Kabupaten Solok sudah memadai. Hasil tersebut dapat dilihat dari tindakan penyuluhan dan pembinaan yang dilakukan apabila didapat hasil inspeksi sanitasi rendah dan sedang serta saran pemeriksaan sampel air. Sebagian besar sanitarian masih menguasai teknik pengambilan, pengiriman dan pemeriksaan sampel air. Proses pengambilan sampel air bakteriologis sumur gali memakai botol steril dan sampel air kimia dengan wadah plastik atau jerigen plastik. Sarana dan prasarana serta dana operasional yang tidak tersedia dalam pelaksanaan tugas di lapangan sehingga membuat kemampuan dan keterampilan yang dimiliki kurang terasah.

Pelatihan yang dibutuhkan oleh sanitarian adalah pelatihan teknis perbaikan dan pengawasan kualitas air serta pelatihan manajemen kesehatan lingkungan. Frekwensi pelatihan program penyehatan air perlu ditambah minimal 2 kali setahun dengan jenis pelatihan yang berbeda terutama pelatihan yang menekankan pada praktek bukan teori. Penjajakan kebutuhan pelatihan (need assessment) perlu menjadi perhatian utama bagi dinas kesehatan kabupaten yaitu analisa organisasi, analisa pekerjaan (job analysis), dan analisa pribadi. 10

Sebagian besar sanitarian berpengalaman berhadapan dengan masyarakat ketika penyuluhan dan pembinaan program penyehatan air bersih di lapangan serta menjadi Tim Teknis pada proyek air bersih pedesaan seperti pada proyek WSLIC2 dan Proyek Pengembangan Kecamatan (PPK). Sanitarian yang lama masa tugasnya lebih terampil dan menguasai tugasnya khususnya yang berhubungan dengan masyarakat, sedangkan sanitarian yang masa tugasnya relatif baru lebih menguasai teori pekerjaan. Petugas yang bekerja lebih lama telah menyesuaikan diri dengan pekerjaan mereka, sementara karyawan yang baru belum mempunyai penyesuaian diri sehingga membutuhkan waktu untuk penyesuaian.

\section{Faktor Organisasi}

Kelengkapan sarana dan prasarana sangat diperlukan untuk menunjang pelaksanaan kegiatan program penyehatan air. Apabila hal ini dibiarkan berlanjut, pencapaian sasaran dan target program penyehatan air tidak akan maksimal. Dalam mendukung program penyehatan air, setiap puskesmas seharusnya mempunyai kendaraan operasional sanitarian mengingat medan kerja sanitarian banyak yang jauh dan berat serta tidak ada akses kendaraan umum. Water Test Kit, alat pengambilan dan pengiriman sampel air, alat penyuluhan seperti poster, lembar balik dan audio visual serta alat perbaikan kualitas air/tabung kaporit sangat diperlukan di samping menambah motivasi kerja dan kepercayaan masyarakat terhadap sanitarian yang pada akhirnya meningkatkan kinerja sanitarian puskesmas.

Imbalan yang diberikan kepada sanitarian sebaiknya tidak hanya dalam bentuk materi, tetapi juga imbalan non materi seperti peningkatan karir dan promosi. Imbalan dana opersional harus diberikan sesuai dengan kebutuhan lapangan misalnya tiga kali dalam seminggu dan pembayaran tanpa ada potongan dari bendaharawan maupun kepala puskesmas. Imbalan ekstrinsik dan intrinsik dapat digunakan untuk memotivasi prestasi kerja, imbalan harus dinilai oleh orang yang bersangkutan dan harus berkaitan dengan tingkat prestasi. ${ }^{4}$

Pemberian tugas rangkap dapat dilakukan, asal pelaksanaan dapat sejalan dengan kegiatan sanitarian di lapangan, misalnya kegiatan promosi kesehatan. Kegiatan tambahan yang sifatnya lebih banyak berhubungan dengan administrasi keuangan dan administrasi obat akan sangat mengganggu pelaksanaan kegiatan pokok sanitarian, sebab tugas tambahan tersebut juga menjadi tanggung jawab penuh sanitarian. Penambahan jumlah petugas menurut jenis program puskesmas perlu menjadi pertimbangan bagi dinas kesehatan kabupaten sehingga setiap petugas bekerja berdasarkan tugas pokok dan fungsinya, dan mengingat tugas sanitarian di masa yang akan datang akan lebih berat terutama untuk menyongsong pelaksanaan Program Jorong Siaga di Kabupaten Solok. Beban kerja berkaitan dengan tugas pokok dan tugas tambahan yang menjadi tanggung jawab seseorang pelaksana kegiatan. ${ }^{11}$

Supervisi oleh dinas kesehatan kabupaten sebaiknya dilakukan tiga atau empat kali setahun. Supervisor harus menguasai teknik dan metode yang sesuai dengan kebutuhan serta membuat check list kegiatan yang akan disupervisi. Serta mempunyai kemampuan teknis, komunikatif dan dapat menjadi motivator bagi sanitarian puskesmas untuk bekerja lebih giat. Hasil laporan sanitarian hendaknya diberikan feedback berupa surat atau ditindaklanjuti ke puskesmas oleh petugas kabupaten dan mencari jalan keluar apabila dijumpai masalah di lapangan. 


\section{Faktor Psikologis \\ Motivasi}

Penelitian ini dapat diketahui bahwa motivasi sanitarian puskesmas dalam melaksanakan tugas program penyehatan air sangat rendah, sehingga hasil kerja/kinerja sanitarian sangat rendah dan tidak mencapai target. Sanitarian puskesmas dapat bekerja lebih baik dan termotivasi apabila tercukupi kebutuhan pokok dalam pelaksanaan program penyehatan air terlebih dahulu terutama kebutuhan sarana dan prasarana, dana operasional, kebutuhan akan penghargaan dari pimpinan dan rekan sekerja. Motivasi individu tidak terletak pada sederetan penggerak, tetapi lebih dititikberatkan pada hierarki kebutuhan tertentu yang lebih tinggi diaktifkan untuk memperluas kebutuhan lain yang lebih rendah dan sudah terpuaskan. ${ }^{12}$ Untuk memaksimalkan motivasi, orangorang perlu mempersepsikan bahwa upaya yang mereka keluarkan akan menghasilkan evaluasi kinerja yang menguntungkan dan bahwa evaluasi yang menguntungkan tersebut akan menghasilkan imbalan yang mereka hargai. 4

Peran dinas kesehatan kabupaten dalam memotivasi sanitarian dapat dilakukan melalui supervisi yang teratur dan terarah serta memberikan feedback kegiatan yang dilaporkan sanitarian. Kebijakan dinas kesehatan kabupaten terutama kebijakan alokasi dana opersional sanitarian puskesmas harus disesuaikan dengan kebutuhan ril di lapangan, melengkapi sarana dan prasarana pendukung kegiatan sanitarian puskesmas seperti Water Test Kit, alat penyuluhan berupa audio visual, kendaraan operasional serta menjadikan sanitarian sebagai tenaga fungsional lebih fokus bekerja sebagai sanitarian dengan pemberian insentif dalam bentuk lain seperti promosi untuk pendidikan guna menambah wawasan dan transformasi ilmu dan pemilihan sanitarian teladan perlu dipertimbangkan oleh dinas kesehatan kabupaten serta untuk memotivasi sanitarian.

Penelitian ini menunjukan sikap setuju dan mendukung hal di atas, namun kenyataannya hasil penilaian kinerja sanitarian puskesmas tetap masih rendah. Hal ini diakibatkan karena untuk merubah sikap menjadi suatu perbuatan diperlukan faktor pendukung. ${ }^{10}$

\section{Kesimpulan}

Kinerja petugas sanitasi puskesmas dalam program penyehatan air di Kabupaten Solok masih rendah. Cakupan air bersih oleh kepala keluarga tertinggi di Puskesmas Jua Gaek. Cakupan inspeksi sanitasi tertinggi di Puskesmas Sungai Lasi. Proporsi kualitas bakteriologis air bersih yang memenuhi syarat yang tertinggi tahun 2004 sampel air SGL, tahun 2005 sampel air PDAM, tahun 2006 sampel air Non PDAM. Proporsi Pokmair tertinggi tahun 2006 di Puskesmas Talang Babungo. Proporsi kelompok pemakai air aktif tertinggi tahun
2006 adalah Puskesmas Selayo. Kemampuan dan keterampilan sanitarian puskesmas terkendala oleh sarana dan prasarana yang kurang, sehingga sebagian besar pelaksanaan kegiatan program tidak dapat dilakukan. Pelatihan program penyehatan air sangat rendah dan tidak sesuai dengan pelatihan teknis dan manajemen program yang dibutuhkan. Pekerja dengan masa tugas yang lebih besar dari 5 tahun cendrung berkinerja baik. Sarana dan prasarana pendukung sangat kurang sehingga pekerjaan tidak dapat dilakukan dengan baik. Imbalan yang diterima sangat kurang. Sanitarian mendapat tugas rangkap. Motivasi sanitarian rendah, perhatian kepala puskesmas kurang, dana opersional, supervisi tanpa feedback, perubahan perilaku dalam bentuk kinerja masih kurang.

\section{Saran}

Pelaksanaan Kebijakan Tiga Pilar Pembangunan Kabupaten Solok Tahun 2006 - 2010 dilakukan melalui evaluasi, monitoring dan berkesinambungan. Pelaksanaan kebijakan air bersih diintegrasikan dengan kegiatan puskesmas yang lain dan didukung sarana dan prasarana, dana opersional; pengembangan sistem informasi kesehatan; pengangkatan sanitarian berdasarkan kebutuhan luas wilayah dan jumlah penduduk. Perlu dilakukan supervisi yang berkesinambungan pembuatan panduan teknis, pelatihan yang sesuai kebutuhan, pengadaan sarana dan prasarana reward. Pemberian bimbingan, supervisi dan umpan balik. Meningkatkan mutu layanan dengan pendekatan mutu terpadu. Menumbuhkan rasa tanggung jawab dan memotivasi pelaksanaan program penyehatan air.

\section{Daftar Pusktaka}

1. Departemen Kesehatan RI. Terjadi KLB diare di Solok Sumbar, sedangkan Surabaya tidak ada KLB diare. 2007 [edisi 20 November 2004, diakses tanggal 13 Juli 2007]. Diunduh dari: http://www. depkes.go.id/index.php.

2. Gaspersz, Vincent. Manajemen kualitas dalam industri jasa. Jakarta: Gramedia Pustaka Utama; 1997.

3. Ilyas, Yaslis. Kinerja: teori, penilaian dan penelitian. Depok: Pusat Kajian Ekonomi Kesehatan FKM UI; 2001.

4. Gibson, James L. Organisasi: perilaku, struktur, dan proses. Terjemahan Djarkasih. Jilid I. Edisi ke Lima. Jakarta: Erlangga; 1987.

5. Departemen Kesehatan RI. Indikator Indonesia sehat 2010 dan pedoman penetapan indikator propinsi sehat dan kabupaten/kota sehat. Jakarta: Departemen Kesehatan RI; 2003.

6. Pemda Kabupaten Solok. Kebijakan strategis pembangunan, sasaran utama pembangunan Kabupaten Solok Tahun 2006-2010. Sumatera Barat: Bappeda Kabupaten Solok, Aro Suka; 2006.

7. Moleong, Lexy J. Metodologi penelitian kualitatif. Edisi Revisi. Bandung: Remaja Rosdakarya; 2004.

8. Badan Pusat Statistik. Statistik kesejahteraan rakyat, survei sosial ekonomi nasional. Jakarta: BPS; 2005. 
9. Departemen Kesehatan RI. Rencana strategis departemen kesehatan 2005-2009. Jakarta: Departemen Kesehatan RI; 2005.

10. Notoatmodjo, Soekidjo. Dasar-dasar pendidikan dan pelatihan. Depok: Badan Penerbit Kesehatan Masyarakat FKM UI; 1989.
11. Azwar, Azrul. Menjaga mutu pelayanan kesehatan. Jakarta: Pustaka Sinar Harapan; 1996.

12. Maslow, AH. Motivasi dan perilaku. Dahara Prize; 1992. 